\title{
Effects of simultaneous supplementation of laying hens with a-linolenic acid and eicosapentaenoic acid/docosahexaenoic acid resources on egg quality and n-3 fatty acid profile
}

\author{
Pingping Zhang', Chuanqiu Tang', Zongqing Ding', Hui Huang ${ }^{2}$, and Yong Sun ${ }^{1, *}$
}

\begin{abstract}
* Corresponding Author: Yong Sun Tel: +86-0719552300, Fax: +86-7198846038, E-mail: sunyong_34@163.com
\end{abstract}

'Department of Chemical, Biological \& Environmental Engineering, Hanjiang Normal University, Hubei, Shiyan 442000, China

${ }^{2}$ Key Laboratory of Algal Biology, Institute of Hydrobiology, Chinese Academy of Sciences, Wuhan, Hubei 430072, China

Submitted Oct 15, 2015; Revised Nov 15, 2015; Accepted Dec 17, 2016
Objective: The aim of this study was to investigate the effects of simultaneous supplementation of laying hens with alpha-linolenic acid (ALA) resources (flax, perilla, and Eucommia ulmoides [E. ulmoides] seeds) and eicosapentaenoic acid/docosahexaenoic acid (EPA/DHA) resources (Schizochytrium sp.) on egg quality and n-3 polyunsaturated fatty acids (PUFA) profile. Methods: Dietary treatments were as follows: i) diet C (control diet); ii) diet F (diet C+10\% flaxseeds); iii) diet P, (diet C+10\% perilla seeds); iv) diet $\mathrm{E}$ (diet $\mathrm{C}+10 \%$ E. ulmoides seeds); v) diet $\mathrm{A}$ (diet $\mathrm{C}+1.5 \%$ microalage); vi) diet $\mathrm{AF}$ (diet $\mathrm{C}+10 \%$ flaxseeds $+1.5 \%$ microalage); vii) diet $\mathrm{AP}$ (diet $\mathrm{C}+10 \%$ perilla seeds $+1.5 \%$ microalgae); viii) diet $\mathrm{AE}$ (diet $\mathrm{C}+10 \%$ E. ulmoides seeds+ $1.5 \%$ microalage).

Results: Egg weight, yolk weight and production ratio were not significantly affected by either algae or in combination with seeds ( $>>0.05)$. No significant difference was observed in ALA and DHA concentration in eggs between flaxseed, perila, and $E$. ulmodies seeds supplementation alone ( $p>0.05)$. N-3 PUFA in eggs was slightly improved by microalgae supplementation. The best supplementation, a combination of microalgae and perilla seeds, elevated $(\mathrm{p}<0.05)$ ALA from 19.7 to $202.5 \mathrm{mg} /$ egg and EPA+DHA from 27.5 to $159.7 \mathrm{mg} /$ egg. Highest n-3 PUFA enrichment $(379.6 \mathrm{mg} / \mathrm{yolk})$ was observed with supplementation of a combination of perilla seed and microalgae (362.2 mg/yolk), followed by a combination of flaxseed and microalgae (348.4 $\mathrm{mg} /$ yolk). The ALA, EPA, and DHA content obtained with a combination of microalgae and seeds surpassed the total sum of that obtained with microalgae or ALA-seeds alone.

Conclusion: It is feasible to enrich eggs with n-3 PUFAs by perilla or E. ulmodies seeds instead of flaxseeds. Simultaneous supplementation of microalgae and seeds helped improve the transfer from EPA and docosapentaenoic acid into DHA.

Keywords: Egg Yolk; Eucommia ulmodies; Flaxseed; Perilla; Schizochytrium sp.; n-3 Polyunsaturated Fatty Acids

\section{INTRODUCTION}

The fatty acid profile of the hen's egg is highly dependent on the fat sources in the feed given to laying hens [1]. Owing to the beneficial implication of long-chain $n-3$ polyunsaturated fatty acids (PUFAs), especially eicosapentaenoic acid (EPA, 20:5n-3) and docosahexaenoic acid (DHA, 22:6 n-3) in human health, omega-3 eggs have gained popularity among customers in recent years [2]. Feeding strategies involve the direct supply of longer-chain DHA/EPA resources like marine microalgae or fish oil, and the supply of precursor alpha-linolenic acid (ALA) resources (plant seeds or seed oil; 18:3 n-3) [3-5] . As regard to plant seeds, most of literature reports concerned the dietary modification by supplementation of flaxseeds [6]. Few data related to the impact of other ALA-rich resources. The search for alternative/complementary sources of ALA has ensued in earnest. 
Algae, mainly heterotrophic microalgae, are another primary natural producer of n-3 PUFA [7]. However, microalgae production cost restricts their application in the production of relatively low-value products such as eggs. Moreover, the conversion efficiency of ALA (18:3n-3) to longer-chain PUFA metabolites is limited in laying hens [8]. Hence, feeding hens with a mixture of seeds and microalgae is an effective and economic way of biofortifying the eggs with nutritionally desired n-3 PUFAs. Prior to now, the impact of the simultaneous supplementation of hen's diet with flaxseed and marine algae as the sources of n-3 PUFAs was rarely reported. Kazmierska and co-workers applied the mixture of linseed oil and fish oil as additives in 2007 [9], whereas the drawback of this enrichment was the unacceptable off-flavor presence in fresh and stored eggs. Gladkowski and co-workers [10] presented the simultaneous supplementation of hen diet with a mixture of flaxseed and marine algae as the sources of n-3 PUFAs. However, there are few reports about the influence of using a mixture of other seeds and microalgae for n-3 LC-PUFA enrichment in eggs.

The details of this study were i) to establish whether it is feasible to enrich eggs with $n-3$ PUFAs by other ALA-rich seeds instead of flaxseed in the diet, and ii) to compare effect of the simultaneous supplementation of seeds and microalgae Schizochytrium sp. on egg quality and fatty acid composition.

\section{MATERIALS AND METHODS}

\section{Animal care}

The experimental procedure was approved by the Institutional Animal Care and Use Committee at Hanjiang Normal University (YYTC/LL 20150856).

\section{Chemicals}

All the solvents and chemicals used were purchased from SigmaAldrich and they were analytical grade, unless specified otherwise.

\section{ALA-rich seeds sample}

Experimental perilla, flax and Eucommia ulmoides (E. ulmoides) seeds were collected from the main producing areas. The dried seeds for gas chromatography-mass spectrometer (GC-MS) analysis were crushed for $40 \mathrm{~s}$ in a coffee grinder with a power of 800 W from Boeng Coffee Equipment Co., Ltd (Yiwu, China). Powdered samples were sieved to select particles smaller than 1,000 $\mu \mathrm{m}$ and were immediately used for the following experiments.

\section{Algae Schizochytrium sp. sample}

The algae biomass (dry basis) was from our laboratory cultivated in a large scale fermentation production. The experiments were carried out in a $50 \mathrm{~L}$ fermentation tank with a working volume of $35 \mathrm{~L}$. The seed culture $(10 \%, \mathrm{v} / \mathrm{v})$ was cultivated for $24 \mathrm{~h}$ in a $10 \mathrm{~L}$ seed fermentation tank. During the fermentation process, intermittent glucose feeding was supplied to keep its concen- tration above $15 \mathrm{~g} / \mathrm{L}$ and performed at $28^{\circ} \mathrm{C}$. The agitation and temperature was controlled by a computer system. The dry product was in light yellow powder with a special flavor of alga.

Fatty acid analysis

A sample of yolk (200 to $250 \mathrm{mg}$ ), microalgae powder (100 to $200 \mathrm{mg}$ ) or ALA-rich seeds power $(50 \mathrm{mg}$ ) was transmethylated with $2 \mathrm{~mL}$ of $4 \%$ sulphuric acid $\left(\mathrm{H}_{2} \mathrm{SO}_{4}\right)$ dissolved in methanol at $80^{\circ} \mathrm{C}$ for $60 \mathrm{~min}$ [11]. The samples were then cooled, and $1 \mathrm{~mL}$ of $\mathrm{n}$-hexane and $1 \mathrm{~mL}$ of water were added to the samples. The hexane layer containing fatty acid methyl esters (FAME) was collected by centrifugation and analyzed via GC-MS (Agilent 7890A/5975C, Santa Clara, CA, USA) with an HP-88 capillary column ( $60 \mathrm{~m} \times 0.25 \mathrm{~mm} \times 0.25 \mu \mathrm{m}$, Agilent, USA). The oven temperature was set at $175^{\circ} \mathrm{C}$, and held for $10 \mathrm{~min}$, then raised to $220^{\circ} \mathrm{C}$ at a rate of $3^{\circ} \mathrm{C} / \mathrm{min}$, and held for $5 \mathrm{~min}$. The injector was maintained at $250^{\circ} \mathrm{C}$ and operated in the splitless mode with the split ratio of 1:20. Helium (>99.999\% pure) was used as the carrier gas at a flow-rate of $1.0 \mathrm{~mL} / \mathrm{min}$. The interface temperature was set at $240^{\circ} \mathrm{C}$ and the detector voltage at $1.50 \mathrm{kV}$. A 4 min solvent cut time was allowed for all analyses. The ionization mode was electron impact $(70 \mathrm{eV})$. The full scan mode $(\mathrm{m} / \mathrm{z} 50$ 500) was used for identification of all target compounds based on their NIST Mass Spectral Database and a 37 component FAME standard mix (Supelco, Bellefonte, PA, USA). The total fatty acids content was calculated by summing up all peaks except for solvent peaks and the results were reported as a weight percentage of the lipid. Nonadecanoic acid (19:0) ethyl ester was added prior to transesterification as an internal standard. The fatty acid concentrations were expressed with whole egg yolk weight throughout the manuscript.

\section{Hens diet formulation and sampling of eggs}

Eighty brown laying hens (Shiyan, China) of 29 weeks of age on the basis of uniform weight $(2.00 \pm 0.10 \mathrm{~kg})$, were housed in individual cages with ad libitum access to water. A $16: 8 \mathrm{~h}$ photoperiod and $18^{\circ} \mathrm{C}$ temperature were maintained through the feeding trial. Seed was roughly mashed with a grinder to improve mixability into feeds and digestibility by the hens. The experimental trial lasted 35 days: 14 days of adaptation and 21 days of supplementation with flax, perilla, E. ulmoides seeds and microalgae, respectively. During the adaptation period, the hens could adapt to the new environmental conditions and the new commercially available standard diet from Chia Tai Group (Xiangyang, China). The standard diets (Table 1) were formulated to meet the requirements for broilers recommended by the Agricultural Trade Standardisation of China (NY/T33-2004). All diets were supplied in mash form. It was worth mentioning that almost no n-3 PUFAs were present in the standard feed. After the adaptation period, the hens were randomly assigned to one of the seven treatment diets ( $n=10$ hens per treatment diet): a control diet C (complete commercially available standard diet), without 
Table 1. Composition and nutrient levels of the basal diets (as-fed basis)

\begin{tabular}{ll}
\hline Item & \\
\hline Ingredient (\%) & 56.70 \\
Ground yellow corn & 33.45 \\
Soybean meal (43.0\% CP) & 2.30 \\
Rapeseed meal (36.5\% CP) & 2.21 \\
Cottonseed meal (40.5\% CP) & 1.84 \\
Rapeseed oil & 0.75 \\
Ground limestone & 1.62 \\
Dicalcium phosphate & 0.22 \\
DL-methionine (98.5\%) & 0.20 \\
Choline chloride & 0.36 \\
NaCl & 0.34 \\
Micronutrient) & \\
Calculated nutrient level (\%) & 21.23 \\
(P) & 12.03 \\
ME (MJ/kg) & 0.95 \\
Calcium & \\
Nonphytate phosphorus & 0.45 \\
Lysine & 1.13 \\
Methionine & 0.47 \\
Methionine and cystine & 0.89 \\
\hline
\end{tabular}

$\mathrm{CP}$, crude protein; $\mathrm{ME}$, metabolizable energy.

1) Provided per kilogram of diet: vitamin A (all-trans retinol acetate), 10,000 IU; cholecalciferol, 2,600 IU; vitamin E (all-rac- $\alpha$-tocopherol acetate), $20 \mathrm{IU}$; vitamin $\mathrm{K}$ (menadione Na bisulfate), $2.0 \mathrm{mg}$; thiamine (thiamine mononitrate), $1.6 \mathrm{mg}$; riboflavin, $6.0 \mathrm{mg}$; vitamin $B_{6}, 3.0 \mathrm{mg}$; vitamin $B_{12}, 0.0014 \mathrm{mg}$; pantothenate, $20 \mathrm{mg}$; niacin, $30 \mathrm{mg}$; folic acid, $0.8 \mathrm{mg}$; biotin, $0.12 \mathrm{mg}$; choline (choline chloride), $500 \mathrm{mg} ; \mathrm{Cu}\left(\mathrm{CuSO}_{4} \cdot 5 \mathrm{H}_{2} \mathrm{O}\right), 8$ $\mathrm{mg} ; \mathrm{Mn}\left(\mathrm{MnSO}_{4} \cdot \mathrm{H}_{2} \mathrm{O}\right), 100 \mathrm{mg} ; \mathrm{Zn}\left(\mathrm{ZnSO}_{4} \cdot 7 \mathrm{H}_{2} \mathrm{O}\right), 40 \mathrm{mg} ; \mathrm{Fe}\left(\mathrm{FeSO}_{4} \cdot 7 \mathrm{H}_{2} \mathrm{O}\right), 80 \mathrm{mg} ; \mathrm{I}(\mathrm{KI})$, $0.35 \mathrm{mg} ; \mathrm{Se}\left(\mathrm{Na}_{2} \mathrm{SeO}_{3}\right), 0.15 \mathrm{mg}$.

${ }^{2)}$ Determined by triplicate analyses.

supplementation of seeds and microalgae. The other six diets supplemented with seeds and microalgae were as follows: F, diet C supplemented with $10 \%$ flaxseeds (w/w); P, diet C supplemented with $10 \%$ perilla seeds (w/w); E, diet $C$ supplemented with $10 \%$ E. ulmoides seeds (w/w); A, diet C supplemented with $1.5 \%$ Schizochytrium sp. (w/w); AF, diet C supplemented with $10 \%$ flaxseeds $+1.5 \%$ Schizochytrium sp. (w/w); AP, diet C supplemented with $10 \%$ perilla seeds $+1.5 \%$ Schizochytrium $(\mathrm{w} / \mathrm{w}) ; \mathrm{AE}$, diet C supplemented with $10 \%$ E. ulmoides seeds $+1.5 \%$ Schizochytrium $(\mathrm{w} / \mathrm{w})$. The concentrations of supplements applied in the diet were established on the basis of previous reports concerning feeding of hens [12-14]. During the feeding period, egg production ratio, yolk weight and egg mass were registered on a daily basis. Moreover, five eggs from each treatment were randomly collected daily for further analysis.

\section{Statistics}

Data were subjected to one-way analysis of variance. A Duncan's multiple range test was used to evaluate differences between groups of discrete variables by the statistical product and service solutions (SPSS 16.0, United States). Mean values and standard errors of means are reported. A value of $\mathrm{p}<0.05$ was considered statistically significant.

\section{RESULTS AND DISCUSSION}

Fatty acid composition of flaxseed, perilla seeds, Eucommia ulmodies seeds, microalgae and control diet used in this experiment

N-3 fatty acid compositions of experimental natural sources of n-3 PUFAs, namely flaxseed and algae are listed in Table 2 . The fatty acid composition of standard diets was characterised by high content of linoleic acid (18:2, n-6) and oleic acid (18:1, $\mathrm{n}-9$ ), that is, $52.17 \%$ and $22.16 \%$, respectively. Among n-3 PUFAs, only ALA (18:3, n-3) was observed, but in minor amount (3.69\%).

The ALA dominated among fatty acids in all seeds and accounted for $58.2 \%, 60.9 \%$, and $59.7 \%$ in flax, perilla, and $E$. ulmodies. The proportion of ALA in perilla seeds was slightly higher than flaxseeds and E. ulmodies seeds. Microalgae, on the other hand, was mainly the source of EPA $(0.72 \%)$ and DHA (6.74\%). Only small amount of ALA was observed in algae (0.50\%).

Egg weight, yolk weight and egg production

Layers fed with diets supplemented with microalgae or seeds showed no significant difference in egg weight and yolk weight ( $>0.05$ ) (Table 3), compared with the control treatment. Layers fed with diets supplemented with microalgae or seeds during 1 to 2 weeks showed no significant difference in egg production, compared with the control treatment ( $\mathrm{p}>0.05)$. However, layers fed with microalgae or seeds showed significantly higher egg production at week 3 (Table 3). Compared with the control diet, diets supplemented with $10 \%$ flaxseeds alone decreased $(\mathrm{p}<0.05)$ production. Supplementation of microalgae alone at $1.5 \%$ caused slightly higher egg production than the other diets.

Effect of feeding AlA resources on egg n-3fatty acids at week 3 The effects of ALA-rich seed supplementation on egg fatty acids are present in Table 4 . There was a clear indication that inclu-

Table 2. Composition of fatty acids (expressed as \% of the total fatty acids) of fodder components applied in feeding of hens

\begin{tabular}{|c|c|c|c|c|c|c|c|c|c|c|c|c|c|c|c|c|c|}
\hline Feed & $12: 0$ & $14: 0$ & $15: 0$ & $16: 0$ & $17: 0$ & $18: 0$ & 18:1 & $18: 2(n-6)$ & $18: 3(n-6)$ & $18: 3(n-3)$ & $20: 0$ & $21: 0$ & $20: 3(n-6)$ & $20: 4(n-6)$ & $22: 0(n-3)$ & $20: 5(n-3)$ & $22: 5(n-3)$ \\
\hline Control diet & ND & 0.11 & ND & 17.80 & 0.16 & 2.53 & 22.16 & 52.17 & 0.08 & 3.69 & ND & ND & ND & ND & ND & ND & ND \\
\hline Algae & 0.20 & 8.95 & 2.19 & 38.01 & 0.85 & 1.47 & ND & 0.23 & 0.23 & 0.59 & 0.52 & 0.33 & 0.32 & 0.49 & 0.39 & 0.72 & 6.74 \\
\hline Flaxseed & ND & 0.07 & 0.05 & 5.10 & 0.08 & 3.30 & 18.10 & 15.30 & 0.18 & 58.2 & 0.18 & ND & ND & ND & 0.14 & ND & ND \\
\hline Perilla seed & ND & 0.06 & 0.03 & 5.94 & 0.06 & 2.20 & 16.21 & 14.72 & 0.20 & 60.93 & 0.20 & ND & ND & ND & 0.03 & ND & ND \\
\hline $\begin{array}{l}\text { Eucommia ulmoides } \\
\text { seeds }\end{array}$ & ND & 0.06 & 0.04 & 7.01 & 0.06 & 3.24 & 10.53 & 20.37 & 0.27 & 59.7 & 0.24 & ND & ND & ND & 0.08 & ND & ND \\
\hline
\end{tabular}

ND, not detected. 
Table 3. Effect of supplementation with ALA and EPA/DHA resources on egg weight, yolk weight (g) and egg production ratio

\begin{tabular}{|c|c|c|c|c|c|c|c|c|c|c|}
\hline & $C^{1)}$ & $F$ & $\mathbf{P}$ & $E$ & A & $\mathrm{AF}$ & $\mathrm{AP}$ & $\mathrm{AE}$ & SEM & $\mathrm{p}$-value \\
\hline \multicolumn{11}{|c|}{ Egg weight (g) } \\
\hline Week 1 & 64.1 & 59.8 & 58.2 & 60.5 & 61.7 & 56.0 & 63.5 & 64.1 & 1.2 & 0.453 \\
\hline Week 2 & 65.3 & 57.3 & 63.8 & 59.1 & 59.9 & 59.2 & 62.9 & 65.3 & 2.0 & 0.216 \\
\hline Week 3 & 63.6 & 59.3 & 59.0 & 64.2 & 57.4 & 63.8 & 62.5 & 63.6 & 0.9 & 0.527 \\
\hline \multicolumn{11}{|c|}{ Yolk weight (g) } \\
\hline Week 1 & 14.3 & 14.5 & 14.4 & 15.9 & 16.1 & 13.4 & 16.8 & 14.3 & 0.35 & 0.059 \\
\hline Week 2 & 14.9 & 15.0 & 15.4 & 15.6 & 14.9 & 13.3 & 15.9 & 14.9 & 0.42 & 0.205 \\
\hline Week 3 & 14.2 & 14.4 & 16.0 & 16.0 & 13.1 & 14.8 & 14.6 & 14.2 & 0.26 & 0.156 \\
\hline \multicolumn{11}{|c|}{ Egg production ratio (\%) } \\
\hline Week 1 & 91.4 & 77.1 & 87.1 & 91.4 & 91.4 & 92.9 & 92.9 & 91.4 & 1.4 & 0.076 \\
\hline Week 2 & 90.0 & 88.6 & 91.4 & 92.9 & 97.1 & 88.6 & 92.9 & 92.9 & 1.1 & 0.564 \\
\hline Week 3 & $95.7^{\text {bc }}$ & $78.6^{\mathrm{a}}$ & $81.4^{\mathrm{ab}}$ & $97.1^{c}$ & $98.6^{c}$ & $92.9^{b c}$ & $94.3^{b c}$ & $90.0^{\mathrm{abc}}$ & 1.5 & 0.001 \\
\hline
\end{tabular}

ALA, alpha-linolenic acid; EPA, eicosapentaenoic acid; DHA, docosahexaenoic acid; SEM, standard errors of means.

${ }^{1)} \mathrm{C}$, control diet; F, diet C supplemented with 10\% flaxseeds (w/w); P, diet C supplemented with 10\% perilla seeds (w/w); E, diet C supplemented with 10\% Eucommia ulmoides seeds (w/ w); A, diet C supplemented with 1.5\% Schizochytrium sp. (w/w); AF, diet C supplemented with 10\% flaxseeds+1.5\% Schizochytrium sp. (w/w); AP, diet C supplemented with 10\% perilla seeds+1.5\% Schizochytrium (w/w); AE, diet C supplemented with 10\% Eucommia ulmoides seeds+1.5\% Schizochytrium (w/w).

a-c Means with different superscripts within each parameter are significantly different at $p<0.05$.

Table 4. Effect of supplementation with ALA resources on egg n-3 fatty acids at week 3

\begin{tabular}{|c|c|c|c|c|c|c|c|}
\hline \multirow{2}{*}{ Level of $\omega-3$ fatty acids } & \multicolumn{5}{|c|}{ Dietary treaments } & \multirow{2}{*}{ SEM } & \multirow{2}{*}{ p-value } \\
\hline & C (adaptation) & C (experimental) & $F$ & $\mathbf{P}$ & $\mathrm{E}$ & & \\
\hline ALA (mg/egg) & $19.7^{b}$ & $19.7^{\mathrm{b}}$ & $189.8^{\mathrm{a}}$ & $194.9^{\mathrm{a}}$ & $181.0^{\mathrm{a}}$ & 8.8 & $<0.0001$ \\
\hline EPA (mg/egg) & ND & ND & ND & ND & ND & - & - \\
\hline DPA (mg/egg) & $4.0^{c}$ & $4.0^{c}$ & $9.6^{\mathrm{a}}$ & $10.5^{\mathrm{a}}$ & $8.0^{b}$ & 0.1 & 0.0002 \\
\hline DHA (mg/egg) & $27.5^{b}$ & $27.5^{\mathrm{b}}$ & $57.1^{\mathrm{a}}$ & $61.5^{\mathrm{a}}$ & $56.9^{\mathrm{a}}$ & 0.6 & 0.0011 \\
\hline इn-3 PUFA (mg/egg) & $51.2^{c}$ & $51.2^{c}$ & $256.5^{\mathrm{ab}}$ & $266.9^{\mathrm{a}}$ & $245.9^{b}$ & 10.0 & $<0.0001$ \\
\hline
\end{tabular}

ALA, alpha-linolenic acid; SEM, standard error of mean; ND, not detected; EPA, eicosapentaenoic acid; DPA, docosapentaenoic acid; DHA, docosahexaenoic acid; PUFA, polyunsaturated fatty acid.

${ }^{a-c}$ Means with different superscripts within each parameter are significantly different at $p<0.05$.

sion of ALA resources did result in changes in n-3 fatty acid profile of eggs. ALA, docosapentaenoic acid (DPA) and DHA concentration were significantly influenced $(\mathrm{p}<0.05)$ by the diet, whereas EPA was not detected in eggs with any seed supplementation. The DHA and DPA content from diet F, diet P and $\operatorname{diet} \mathrm{E}$ was nearly double those from diet $\mathrm{C}$. There was a 9-fold or so increase in ALA concentration from seed supplemented group compared to control. No significant difference was observed in ALA and DHA concentration between diet F, diet P, and diet $\mathrm{E}$. Experimental egg products developed with diet $\mathrm{P}$ contained the highest amount of ALA (194.9 mg/egg yolk) compared to the other experimental egg products (diet E, $194.9 \mathrm{mg} / \mathrm{egg}$ yolk; diet F, $194.9 \mathrm{mg} / \mathrm{egg}$ yolk). The highest enrichment of $\mathrm{n}-3$ PUFA, mainly ALA, was achieved by supplementation of diet $\mathrm{P}$, less rich in EPA and DHA. A lower enrichment was obtained by supplementation with diet $\mathrm{E}$ and diet $\mathrm{F}$, probably because of the hardly digestible cell wall of flaxseed and E. ulmodies. Based on the results above, it can be concluded that perilla and E. ulmoides seeds are also excellent sources of ALA to fortify egg yolk with n-3 fatty acids, especially perilla seeds.

Effect of feeding microalgae with or without ALA-rich seeds on egg fatty acids at week 3

In the present study, n-3 fatty acid concentrations in eggs were found to be significantly increased by microalgae supplementation (Table 5). Inclusion of $1.5 \%$ microalgae in control diet (diet A) led to a 2.8-, 1.8-fold, and 1.6-fold increase in DPA, EPA, and DHA of eggs, $(p<0.05)$ respectively, while ALA showed a non-significant difference $(p>0.05)$. Similar results were observed for fish oil, which is also rich in EPA and DHA [15]. The EPA content in the egg yolks increased significantly when hens were fed with microalgae $(\mathrm{p}<0.05)$, whereas EPA was not detected in eggs of hens fed diet C and ALA-rich seeds. It should also be noted that DPA was detected in all microalgae or seeds enriched eggs, besides the control group. DPA is an intermediate in the conversion process of EPA to DHA. This may indicate that not only the conversion of ALA to n-3 LC-PUFA is a rate limiting step, but also is the conversion of EPA to DHA. Microalgae-fed hens incorporated 3-fold more DHA in eggs compared with ALA-fed hens.

Better yet, microalgae supplementation in combination with ALA-rich seeds has a more prominent effect than microalgae supplementation alone. N-3 PUFA concentration increased substantially after supplementation of seeds into $\operatorname{diet} \mathrm{A}$, showing 
Table 5. Effect of supplementation with ALA and EPA/DHA resources on egg n-3 fatty acids at week 3

\begin{tabular}{|c|c|c|c|c|c|c|c|}
\hline \multirow{2}{*}{ Level of $\omega-3$ fatty acids } & \multicolumn{5}{|c|}{ Dietary treaments } & \multirow{2}{*}{ SEM } & \multirow{2}{*}{$p$-value } \\
\hline & C (experimental) & A & $\mathrm{AF}$ & AP & $\mathrm{AE}$ & & \\
\hline ALA (mg/egg) & $19.7^{c}$ & $22.6^{c}$ & $196.3^{\mathrm{ab}}$ & $202.5^{a}$ & $187.5^{b}$ & 7.7 & $<0.001$ \\
\hline EPA (mg/egg) & $N D$ & $10.8^{\mathrm{a}}$ & $6.0^{b}$ & $6.1^{\mathrm{b}}$ & $6.0^{b}$ & 0.1 & 0.0005 \\
\hline DPA (mg/egg) & $4.0^{d}$ & $15.2^{\mathrm{a}}$ & $10.2^{\mathrm{bc}}$ & $11.3^{b}$ & $9.6^{c}$ & 0.1 & 0.0002 \\
\hline DHA (mg/egg) & $27.5^{\mathrm{d}}$ & $72.2^{c}$ & $149.7^{b}$ & $159.7^{\mathrm{a}}$ & $145.3^{b}$ & 6.1 & 0.0023 \\
\hline En-3 PUFA (mg/egg) & $51.2^{\mathrm{e}}$ & $120.8^{d}$ & $362.2^{b}$ & $379.6^{\mathrm{a}}$ & $348.4^{c}$ & 16.1 & $<0.001$ \\
\hline
\end{tabular}

ALA, alpha-linolenic acid; EPA, eicosapentaenoic acid; DHA, docosahexaenoic acid; SEM, standard error of mean; ND, not detected; PUFA, polyunsaturated fatty acid.

${ }^{\text {a-d }}$ Means with different superscripts within each parameter are significantly different at $p<0.05$.

a significant difference for the level of ALA and DHA in the eggs $(\mathrm{p}<0.05)$. An average increase of approximately 9-fold and 5-fold in ALA concentration and DHA concentration of eggs was observed as compared to the control diet, respectively. Also, inclusion of seeds into diet A resulted in a slight decrease in EPA concentration (10.8 mg/egg yolk vs 6.0 to $6.1 \mathrm{mg} / \mathrm{egg}$ yolk) and a significant decrease in DPA concentration in eggs $(15.2 \mathrm{mg} / \mathrm{egg}$ yolk vs 9.6 to $11.3 \mathrm{mg} / \mathrm{egg}$ yolk) with microalgae alone, respectively. We were also encouraged that there was a positive influence of simultaneous supplementation of microalgae and seeds on the $\mathrm{n}-3$ PUFA composition in eggs. As $1.5 \%$ E. ulmodies seed was added into diet $\mathrm{A}$, the obtained DHA content ( $145.3 \mathrm{mg} / \mathrm{egg}$ yolk) surpassed the total sum of that obtained with diet A $(72.2 \mathrm{mg} / \mathrm{egg}$ yolk) and diet E (56.9 mg/egg yolk). These combined dietary treatments also exerted $(\mathrm{p}<0.05)$ similar impacts in diet $\mathrm{AF}$ and diet AE. Hence, simultaneous addition of seeds and microalgae can help improve the transfer from EPA and DPA into DHA in egg yolks. However, more research is needed to confirm this hypothesis. In addition, the highest n-3 PUFA enrichment (379.6 $\mathrm{mg} /$ egg yolk) was observed $(\mathrm{p}<0.05)$ with supplementation of a combination of perilla seed and microalgae (diet AP), followed by a combination of flaxseed and microalgae (diet AF). In conclusion, our results suggests that a combination of algae and seeds has a greater positive effect on egg n-3 fatty acids than either algae or seeds alone.

Furthermore, we achieved significantly higher enrichment of DHA than those previously reported for eggs. The best DHA content from diet AF fed with 1.5\% microalgae and 10\% flaxseed in control diet was $159.7 \mathrm{mg} /$ yolk. Kim and co-workers applied $3 \%$ addition of flaxseed oils and different ratio of microalgae in feeding of laying hens [16]. They achieved DHA content in the range of $118 \mathrm{mg}$ (using 7.5\% Algae B) to $127 \mathrm{mg}$ (using 7.5\% Algae C) per egg yolk.

\section{CONCLUSION}

In summary, our study has developed a new combined use of three kinds of ALA-rich seeds and EPA/DHA-rich microalgae in producing $\mathrm{n}-3$ fatty acids-enriched eggs without affecting the performance or health of hens. Eggs from hens fed with a combination of miroalgae and perilla seeds produced by our described procedure contained up to $202.5 \mathrm{mg}$ ALA and $170.5 \mathrm{mg}$ EPA+ DHA, whereas there was only $19.7 \mathrm{mg}$ ALA and $27.5 \mathrm{mg}$ EPA and DHA in the control eggs. The European Food Safety Authority recommends an intake of $250 \mathrm{mg} / \mathrm{d} \mathrm{EPA}$ and DHA [17]. Thus, ingesting one of our fortified eggs will meet $68 \%$ of the daily recommendations for EPA+DHA. Results of the study also revealed that simultaneous supplementation of microalgae and seeds helped to improve the transfer from EPA and DPA into DHA in egg yolks. These extra benefits of a combination of microalgae and AlA-rich seeds warrant further investigations

\section{CONFLICT OF INTEREST}

We certify that there is no conflict of interest with any financial organization regarding the material discussed in the manuscript.

\section{ACKNOWLEDGMENTS}

This research is supported by the Research Foundation of Education Bureau of Hubei Province, China (Grant No. Q20135001).

\section{REFERENCES}

1. Gonzalez-Esquerra R, Leeson S. Studies on the metabolizable energy content of ground full-fat flaxseed fed in mash, pellet, and crumbled diets assayed with birds of different ages. Poult Sci 2000;79:1603-7.

2. Surai PF, Sparks NHC. Designer eggs: from improvement of egg composition to functional food. Trends Food Sci Technol 2001;12: 7-16.

3. Li, MH, Robinson EH, Tucker CS, Manning BB, Khoo L. Effects of dried algae Schizochytrium sp., a rich source of docosahexaenoic acid, on growth, fatty acid composition, and sensory quality of channel catfish Ictalurus punctatus. Aquaculture 2009;292:232-6.

4. Lemahieu C, Bruneel C, Termote-Verhalle R, et al. Impact of feed supplementation with different omega-3 rich microalgae species on enrichment of eggs of laying hens. Food Chem 2013;141:4051-9.

5. Yi H, Hwang KT, Regenstein JM, Shin SW. Fatty acid composition and sensory characteristics of eggs obtained from hens fed flaxseed oil, dried whitebait and/or fructooligosaccharide. Asian-Australas J Anim Sci 2014;27:1026-34.

6. Hayat Z, Cherian G, Pasha TN, Khattak FM, Jabbar MA. Effect offee- 
ding flax and two types of antioxidants on egg production, egg quality, and lipid composition of eggs. J Appl Poult Res 2009;18:541-51.

7. Rizzi L, Bochicchio D, Bargellini A, Parazza P, Simioli M. Effects of dietary microalgae, other lipid sources, inorganic selenium and iodine on yolk n-3 fatty acid composition, selenium content and quality of eggs in laying hens. J Sci Food Agric 2009;89:1775-81.

8. Fraeye I, Bruneel C, Lemahieu C, et al. Dietary enrichment of eggs with omega-3 fatty acids: A review. Food Res Int 2012;48:961-9.

9. Kazmierska M, Korzeniowska M, Trziszka T, Jarosz B. Effect of fodder enrichment with PUFAs on quail eggs. Polish J Food Nutr Sci 2007; 57:281-4.

10. Gładkowski W, Kiełbowicz G, Chojnacka A, et al. The effect of feed supplementation with dietary sources of $n-3$ polyunsaturated fatty acids, flaxseed and algae Schizochytrium sp., on their incorporation into lipid fractions of japanese quail eggs. Int J Food Sci Technol 2014; 49:1876-85.

11. Liang KH, Zhang QH, Gu M. Effect of phosphorus on lipid accumulation in freshwater microalga Chlorella sp. J Appl Phycol 2013;25: 311-8.

12. Bean LD, Leeson S. Long term effects of feeding flaxseed on performance and egg fatty acid composition of brown and white hens. Poult
Sci 2003;82:388-94.

13. Park JH, Upadhaya SD, Kim IH. Effect of dietary marine microalgae (Schizochytrium) powder on egg production, blood lipid profiles, egg quality, and fatty acid composition of egg yolk in layers. AsianAustralas J Anim 2015;28:391-7.

14. Parpinello GP, Versari A, Sirri F, Tallarico N, Meluzzi A. Sensory evaluation of egg products and eggs laid from hens fed diets with different fatty acid composition and supplemented with antioxidants. Food Res Int 2006;39:47-52.

15. Cachaldora P, Garcíarebollar P, Alvarez C, De Blas JC, Méndez J. Effect of type and level of basal fat and level of fish oil supplementation on yolk fat composition and n-3 fatty acids deposition efficiency in laying hens. Anim Feed Sci Technol 2008;141:104-14.

16. Kim J, Magnuson A, Tao L, Barcus M, Lei XG. Potential of combining flaxseed oil and microalgal biomass in producing eggs-enriched with n-3 fatty acids for meeting human needs. Algal Res 2016;17:31-7.

17. Ryan AS, Astwood JD, Gautier S, et al. Effects of long-chain polyunsaturated fatty acid supplementation on neurodevelopment in childhood: A review of human studies. Prostaglandins Leukot Essent Fatty Acids 2010;82:305-14. 